\title{
A comparative study on the tip position of peripherally inserted central catheter inserted at two forward P-wave amplitudes by intracavitary electrocardiogram in cancer patients
}

\author{
Xinpeng Wang ${ }^{1 \#}$, Yong Yang ${ }^{2 \#}$, Jing Dong ${ }^{1}$, Xiaozheng Wang ${ }^{1}$, Yuanyuan Zheng ${ }^{1}$, Jie Chen ${ }^{1}$, Yanfen Shen ${ }^{1}$, \\ Hongzhi Wang ${ }^{1,2}$
}

${ }^{1}$ Vascular Access Center (VAC), Key Laboratory of Carcinogenesis and Translational Research (Ministry of Education/Bejing), Peking University Cancer Hospital \& Institute, Beijing, China; ${ }^{2}$ Department of Critical Care Medicine (ICU), Key Laboratory of Carcinogenesis and Translational Research (Ministry of Education/Bejing), Peking University Cancer Hospital \& Institute, Beijing, China

Contributions: (I) Conception and design: X Wang, Y Yang; (II) Administrative support: Y Shen, H Wang; (III) Provision of study materials or patients: X Wang, J Dong, X Wang, Y Zheng, J Chen; (IV) Collection and assembly of data: X Wang, J Dong, X Wang, Y Zheng, J Chen; (V) Data analysis and interpretation: Y Yang, H Wang; (VI) Manuscript writing: All authors; (VII) Final approval of manuscript: All authors.

\#These authors contributed equally to this work.

Correspondence to: Yanfen Shen; Hongzhi Wang. Peking University Cancer Hospital \& Institute, No.52 of Fucheng Road, Haidian District, Beijing 100142, China. Email: shenyanfen1205@163.com; Doctorwhz@sina.com.

Background This study aimed to compare the tip location of peripherally inserted central catheter (PICC) under two forward $\mathrm{P}$-wave amplitudes ( $\mathrm{P}$-wave amplitude is the autonomous peak or $\mathrm{P}$-wave amplitude is $50-80 \%$ of the QRS main wave) by intracavitary electrocardiogram (IC-EKG) to determine the PICC tip in optimal location thus avoiding catheter-related complications.

Methods: The data of 300 cancer patients with PICC insertion were collected retrospectively. For the observation group, the position of the catheter tip was left at the level when $\mathrm{P}$ wave amplitude was its autonomous peak (168 patients catheterized in 2018). While for the control group, the catheter tip was left at the level when the $\mathrm{P}$ wave amplitude was $50-80 \%$ of the QRS main wave (132 patients catheterized in 2017). Both groups of patients underwent the chest X-ray examination (CXR) after catheterization. The total compliance rate [PICC tip was located in the lower third of the Superior Vena Cava (SVC) and the Cavo-Atrial Junction (CAJ)], the optimal position compliance rate (PICC tip was located in the CAJ), and the incidence of the catheter tip malposition were compared between the two groups. The complications after catheterization including arrhythmia after catheterization within 24 hours, catheter-related thrombosis, catheter dysfunction, and catheter infection within 90 days were also compared.

Results: There was no difference in the total compliance rate of PICC tip position and the incidence of the catheter malposition in the two groups $(\mathrm{P}>0.05)$. But the optimal position compliance rate of the observation group was higher than that of the control group $(\mathrm{P}<0.05)$. There was no difference in the incidence of arrhythmia after catheterization within 24 hours of the two groups $(\mathrm{P}>0.05)$. The incidence of catheterrelated thrombosis, catheter dysfunction, and catheter infection within 90 days in the observation group was lower than those in the control group $(\mathrm{P}<0.05)$.

Conclusions: The PICC tip position at the autonomous peak of the $\mathrm{P}$ wave is significantly better than that at the $\mathrm{P}$ wave amplitude being $50-80 \%$ of the QRS main wave under the IC-EKG guidance for PICC insertion.

Keywords: Peripherally inserted central catheter (PICC); intracavitary electrocardiogram; P-wave; autonomous peak

Submitted Jul 10, 2021. Accepted for publication Aug 13, 2021.

doi: 10.21037/apm-21-1893

View this article at: https://dx.doi.org/10.21037/apm-21-1893 


\section{Introduction}

IC-EKG positioning technology is the use of a metal guidewire in the catheter as a recording electrode on the EKG, which guides the PICC catheter tip positioning through predictive changes in the $\mathrm{P}$-wave during PICC insertion, reducing catheter malposition to improve the accuracy.

The autonomous peak of the forward $\mathrm{P}$-wave represents the CAJ (1), which is considered to be the ideal position for the PICC tip $(2,3)$. The tip position has almost been determined when the forward P-wave amplitude is $50-80 \%$ of the QRS main wave of IC-EKG, which is located in the lower third of the SVC in many studies $(4,5)$.

Tracheal carina on CXR is an ideal imaging marker for determining the PICC tip position. The CAJ is about $3-5 \mathrm{~cm}$ under the tracheal carina, while the lower third of the SVC is within $3 \mathrm{~cm}$ below the tracheal carina (6-8).

The retrospective study aimed to compare the tip position and complications after PICC insertion at two forward P-wave amplitudes by IC-EKG to identify better approach.

We present the following article in accordance with the STROBE reporting checklist (available at https://dx.doi. org/10.21037/apm-21-1893).

\section{Methods}

\section{Participants}

The study was conducted in accordance with the Declaration of Helsinki (as revised in 2013) and approved by the Institutional Review Board of Peking University Cancer Hospital. Clinical data on 300 cancer patients after PICC insertion from August 2017 to August 2018 who met the inclusion criteria were collected retrospectively.

Inclusion criteria: patients with cavity electrograph positioning indications. The patients signed an informed consent form and volunteered to participate in the study.

Exclusion criteria: patients with severe arrhythmia. Patients who were installed pacemakers. The patient refused to participate in the study.

One hundred and sixty-eight patients catheterized from March, 2018 to August, 2018 (The PICC tip position was determined at the autonomous peak of the forward $\mathrm{P}$-wave) were assigned to the observation group. One hundred and thirty-two patients catheterized during August, 2017 to February, 2018 (The PICC tip position was determined at the $\mathrm{P}$ wave amplitude being $50-80 \%$ of the QRS main wave) were assigned to the control group. All the general data of the two groups were presented in Table 1. There were no significant differences in age, sex, BMI, tumor type, catheter location, puncture veins, catheter type, and history of CVCs between the two groups $(\mathrm{P}>0.05)$.

\section{Catbeterization}

All the PICC insertion was accomplished by the VAC team. Tip positions for all patients were determined by IC-EKG. Three surface electrodes (right arm, left arm, and left leg) and lead II were connected. Braun transducer and switch for shifting from surface ECG tracing to IC-EKG tracing were employed in the study. When the catheter tip entered the SVC, the metal guidewire for PICC insertion was attached to the connector of the transducer (Figures 1,2). When the catheter tip gets close to the lower third of the SVC, the amplitude of $\mathrm{P}$ wave gradually increases into $50-80 \%$ of the QRS main wave in the control group (Figure $3 A$ ), which will reach up to the autonomous peak as the catheter tip getting to the CAJ in the observation group (Figure $3 B$ ). When the catheter tip entered deeply into the right atrium (RA), the $\mathrm{P}$ wave becomes biphasic (Figure 3C).

Both groups of patients had posterior anterior CXR after PICC insertion. On the CXR, the tracheal carina was used as a reliable marker to identify the tip position of PICC. The PICC tip position may be regarded as a suitable position within $5 \mathrm{~cm}$ under the tracheal carina, which was the ideal position when located at $3-5 \mathrm{~cm}$ under the carina especially. The PICC tip position was considered as an inappropriate position if the catheter tip is above the carina (the catheter tip was located in the middle or upper third of the SVC) or deeper more than 5 $\mathrm{cm}$ under the tracheal carina (the catheter tip may enter into the RA).

\section{Statistical analysis}

The data were analyzed using SPSS 26 (IBM Corporation, Armonk, NY, USA). Continuous variables were presented as mean \pm standard deviation and compared with an unpaired $t$-test. Categorical variables were presented as number (percentage) and compared with a $\chi^{2}$ test. The distances from the PICC tip position determined by IC-EKG to the tracheal carina on CXR were recorded. The significance level was at the rate of 0.05 . 
Table 1 General data for both groups of cancer patients

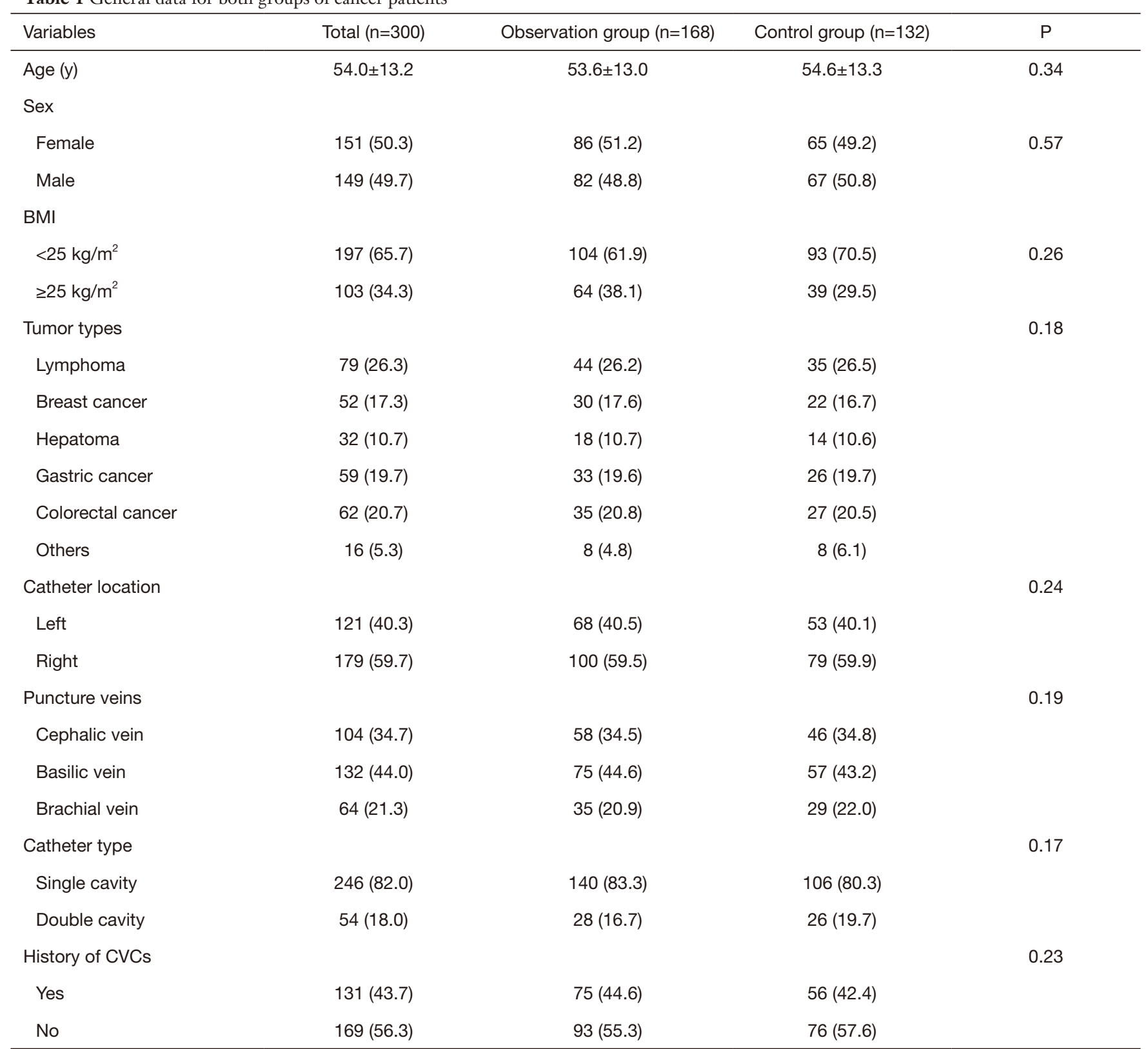

Data were expressed as mean \pm standard deviation, number (percentage). BMI, body mass index; CVCs, central intravenous catheters.

\section{Results}

There was no difference in the total compliance rate of the PICC tip position (the tip position was located in the lower third of the SVC and the CAJ) and the incidence of the catheter malposition (the tip position was located in middle or upper third of the SVC and the RA) between the two groups of patients $(\mathrm{P}>0.05)$. But the optimal position compliance rate (the tip position was located in the CAJ) of the observation group was higher than that of the control group $(\mathrm{P}<0.05)$. All of which can be seen in Table 2.

There was no difference in the incidence of arrhythmia within 24 hours after catheterization of the two groups $(\mathrm{P}>0.05)$. The incidence of catheter-related thrombosis, catheter dysfunction, and catheter infection within 90 days in the observation group was lower than those in the control group $(\mathrm{P}<0.05)$. All of which can be seen in Table 3 . 


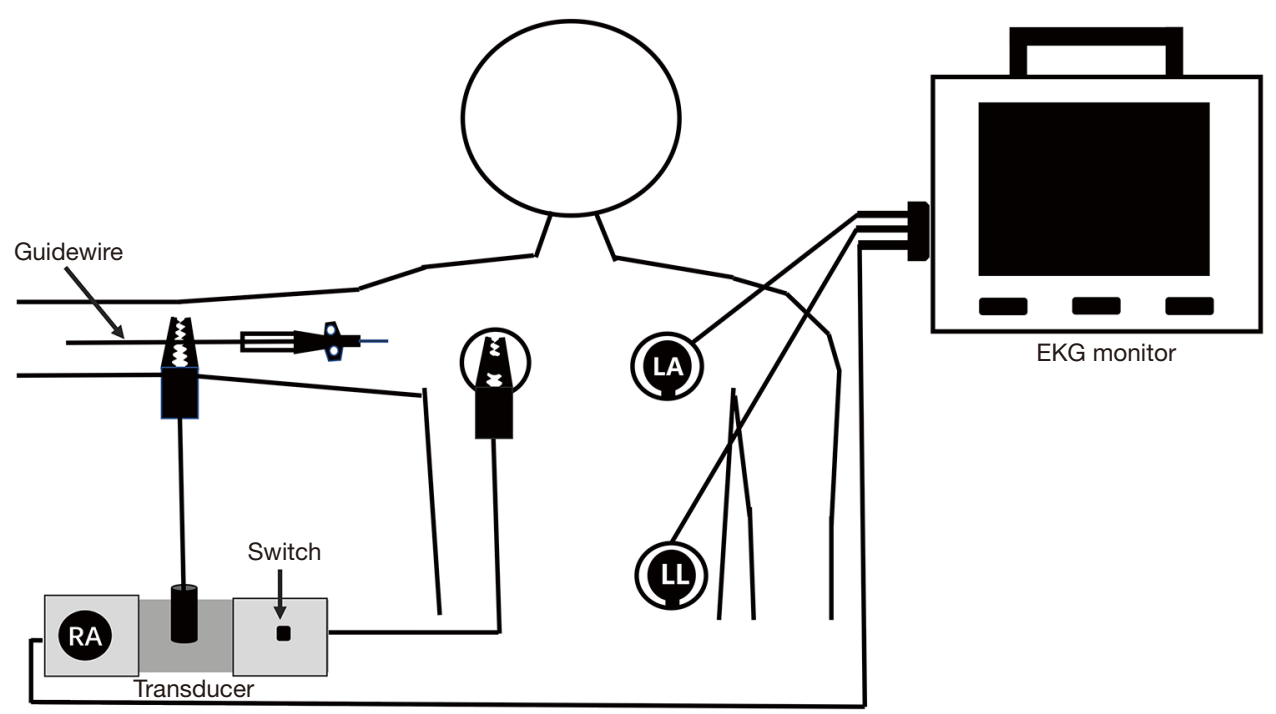

Figure 1 Connection among three electrodes (RA, LA, and LL), guidewire, Braun transducer and EKG-monitor. RA, right arm; LA, left arm; LL, left leg.

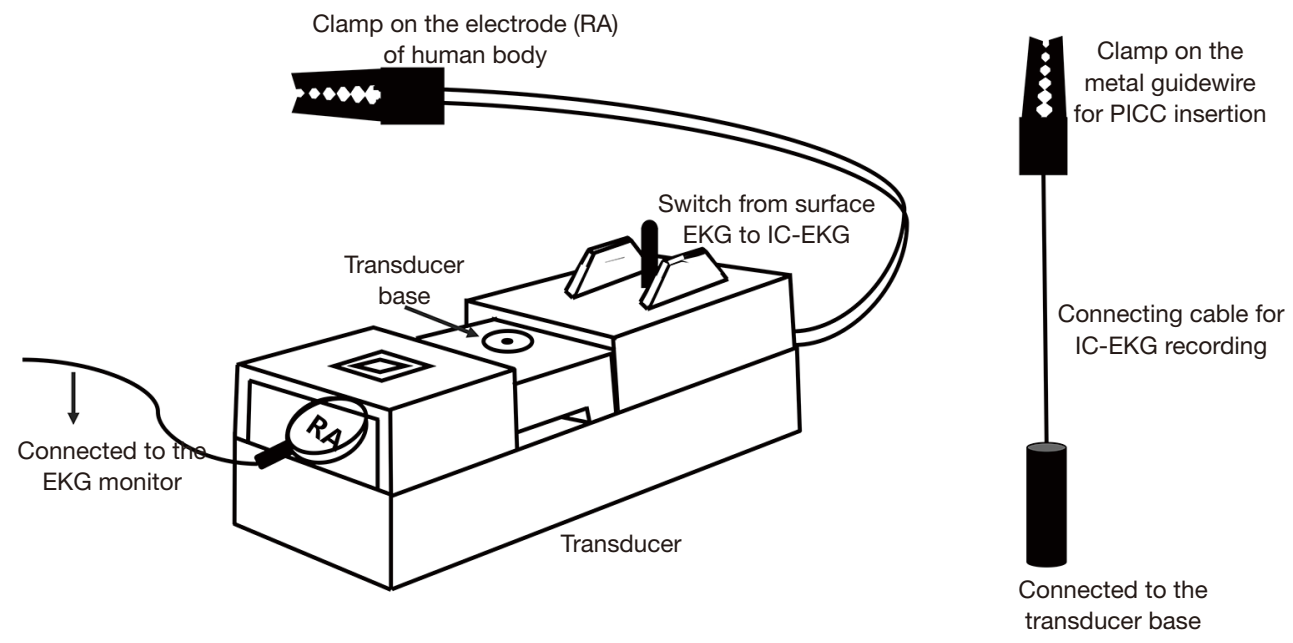

Figure 2 Braun transducer with a switch and its connecting cable.

\section{Discussion}

There are many approaches to determine the PICC tip position, including $\mathrm{X}$-ray fluoroscopy, B-ultrasound positioning and intracavitary electrocardiogram positioning (9). The accuracy of PICC insertion under X-ray fluoroscopy is high. But there is a risk of radiation exposure to both medical staff and patients due to multiple exposures to X-rays during PICC insertion (10). In recent years, the accuracy of IC-EKG guidance or assisted ultrasound positioning to determine the catheter tip position is not lower than that of X-ray fluoroscopy (11). Therefore, X-ray fluoroscopy has been gradually replaced by the former.

With the wide application of PICC, complications caused by catheter tip malposition are increasing. The catheter tip located in the middle or upper third of the SVC, compared with the lower third of the SVC, would increase the incidence of complications such as catheterrelated thrombosis or catheter dysfunction (12). Studies 

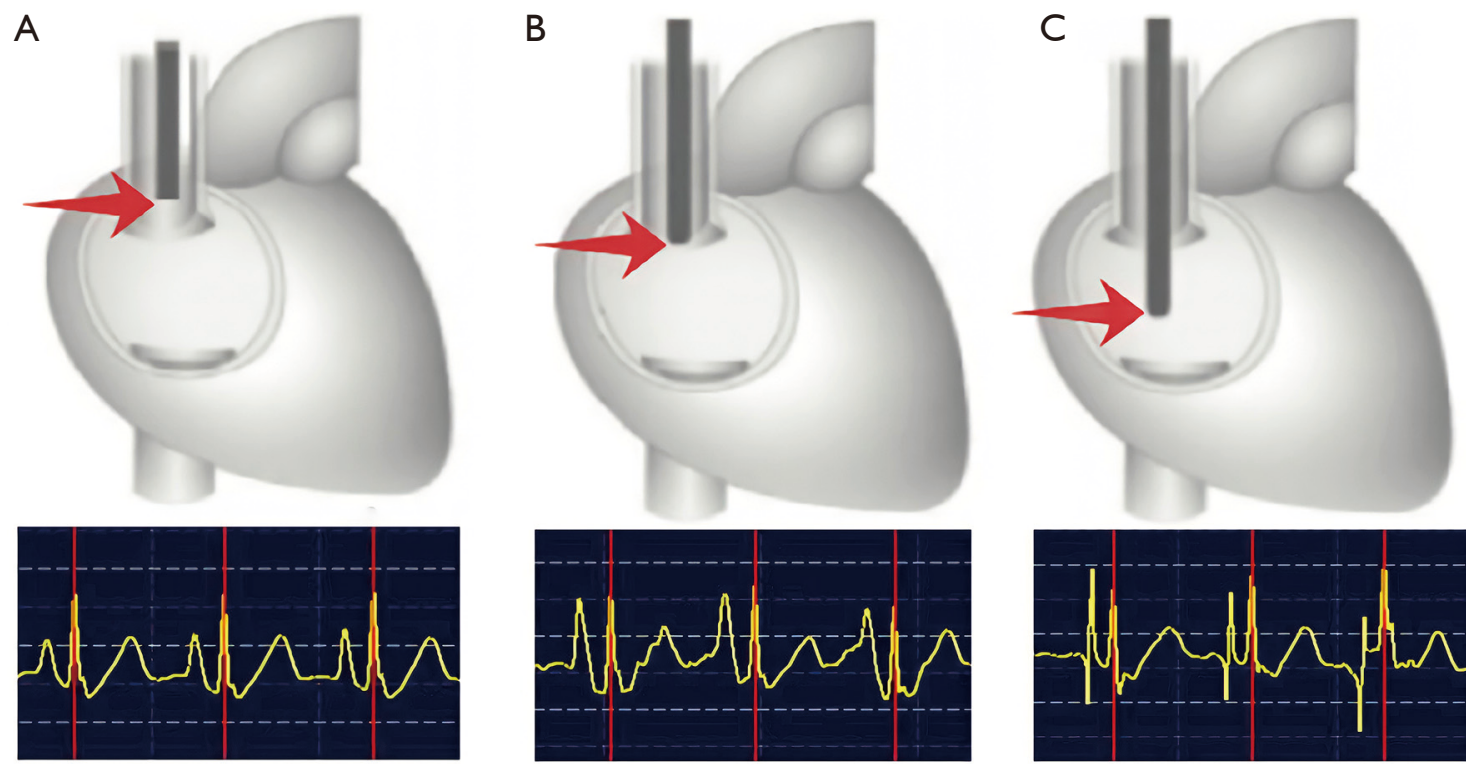

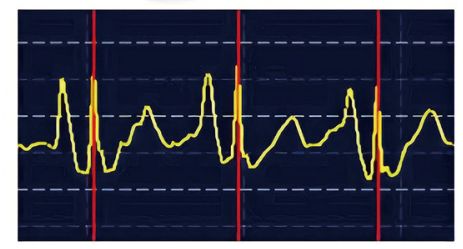

Cavo-Atrial Junction (CAJ)

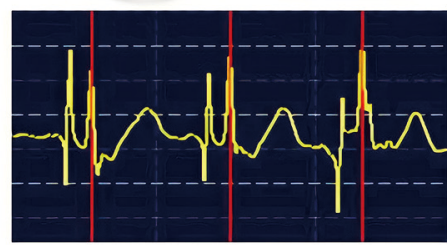

Right Atrium (RA)

Figure 3 Changes of P-waves when the PICC tip was located at three positions by IC-EKG . Red arrow indicates (A) the PICC tip was located in the low third of the SVC, (B) the PICC tip was located at the CAJ, and (C) the PICC tip entered into the RA. RA, right arm; IC-EKG, intracavitary electrocardiogram; PICC, peripherally inserted central catheter; SVC, Superior Vena Cava; CAJ, Cavo-Atrial Junction.

had also shown that the risk of catheter-related thrombosis increases seven times when the catheter tip was located in the middle or upper third of the SVC (13).

At present, most studies confirmed that the PICC tip position located in the lower third of the SVC or the CAJ is considered as a suitable position $(14,15)$. The CAJ is the ideal position for the catheter tip, where the blood flow is greatest and thrombosis risk is the lowest $(16,17)$. This ensures the habitual use of the catheter and avoid catheter dysfunction. The autonomous peak of the P-wave guided by IC-EKG is consistent with the CAJ. We tried to seek a number of studies to identify the CAJ on CXR: Mahlon's study suggested that it was advisable for the center intravenous catheter tip position to be located $4 \mathrm{~cm}$ under the tracheal carina, which was based on the distance of $3.18-4.88 \mathrm{~cm}(95 \% \mathrm{CI})$ from the tracheal carina to the CAJ (18). Baskin's study found that the average distance from tracheal carina to the $\mathrm{CAJ}$ was 2 thoracic vertebral units $\pm 0.4 \mathrm{~cm}(95 \% \mathrm{CI}, 1.5-2.2$ vertebral units, approximately $3.1-5.0 \mathrm{~cm}$ ). There was no difference with the sex, height, weight and surface area in the patients (19). Therefore, with the tracheal carina on CXR as a reference, The CAJ falls in the range of $3-5 \mathrm{~cm}$ under the tracheal carina. The PICC tip position of the two groups of cancer patients in that range ( $3-5 \mathrm{~cm}$ under the carina) was deemed to be located in the CAJ.

The use of IC-EKG had significantly improved the accuracy of PICC tip position (20). The autonomous peak of the P-wave was used to determine the PICC tip position in the observation group, which was considered to be the location of the CAJ (21). The PICC tip position determined at the forward $\mathrm{P}$-wave amplitude being $50-80 \%$ of QRS main wave in the control group, which was considered to be the location of the lower third of the SVC (22). It can be seen that the probability of the PICC tip position in falling at the CAJ in the observation group was significantly higher than that of the control group $(\mathrm{P}<0.05)$. But there was no significant difference in the incidence of catheter malposition in the two groups $(\mathrm{P}>0.05)$. Complications after catheterization were compared in the two groups of patients. There was no difference in the incidence of arrhythmia after catheterization within 24 hours of the two groups $(\mathrm{P}>0.05)$. The incidence of catheter-related thrombosis, catheter dysfunction, and catheter infection within 90 days in the observation group was lower than those in the control group $(\mathrm{P}<0.05)$. 
Table 2 Tip position in both groups of cancer patients confirmed on CXR

\begin{tabular}{|c|c|c|c|c|c|}
\hline Tip position & Total $(n=300)$ & $\begin{array}{l}\text { Observation group } \\
\qquad(n=168)\end{array}$ & $\begin{array}{l}\text { Control group } \\
\quad(n=132)\end{array}$ & $\chi^{2}$ & $P$ \\
\hline Lower third of the SVC & & & & 9.21 & $0.001^{*}$ \\
\hline No & $187(62.3)$ & $146(86.9)$ & $41(31.1)$ & & \\
\hline CAJ & & & & 10.82 & $0.001^{*}$ \\
\hline No & $165(55.0)$ & $45(26.8)$ & $120(90.9)$ & & \\
\hline Middle or upper third of the SVC & & & & 1.15 & 0.42 \\
\hline Yes & $29(9.7)$ & $15(8.9)$ & $14(10.6)$ & & \\
\hline No & 271 (90.3) & $153(91.1)$ & $118(89.4)$ & & \\
\hline Suitable position & & & & 2.12 & 0.33 \\
\hline $\begin{array}{l}\text { Yes (lower third of the SVC } \\
\text { and the CAJ) }\end{array}$ & $258(86.0)$ & $145(86.3)$ & $113(85.6)$ & & \\
\hline $\begin{array}{l}\text { No (middle or upper third of } \\
\text { the SVC and the RA) }\end{array}$ & $42(14.0)$ & $23(13.7)$ & $19(14.4)$ & & \\
\hline
\end{tabular}

Data were expressed as number (percentage). * $\mathrm{P}<0.05$. CAJ, Cavo-Atrial Junction; SVC, Superior Vena Cava; RA, right atrium; CXR, chest X-ray examination.

Table 3 Complications occurred in both groups after PICC insertion

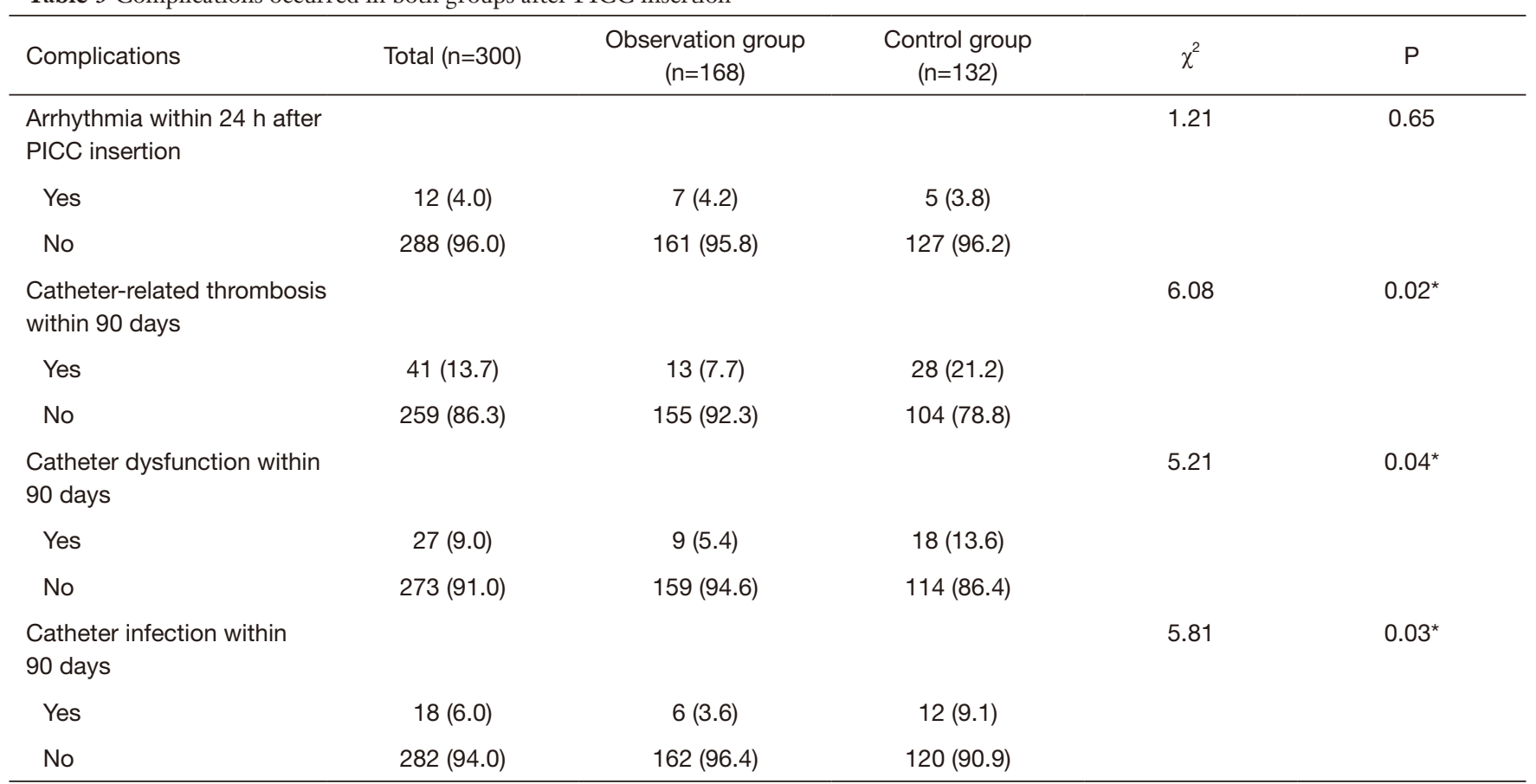

Data were expressed as number (percentage). ${ }^{*}, \mathrm{P}<0.05$. PICC, peripherally inserted central catheter. 


\section{Limitation}

The study compared the PICC tip position and the complications after PICC insertion at two forward P-wave amplitude by intracavitary electrocardiogram in cancer patients. There were few studies like this. However, the study still had some limitations. Firstly, this study was retrospective, with a single center and small sample size. Most of the patients are Han, which had a relatively single ethnic group. Secondly, the distance between the carina on CXR and the tip of the catheter was used to determine whether the catheter tip position was in the different part of the SVC (such as the middle or upper third of the SVC, the lower third of the SVC), the CAJ or the RA. Although numerous studies have shown that the tracheal carina was reliable, there may be some errors in the measurement results. All of the above have to be verified in future work with more sample size and more reliable imaging markers.

\section{Conclusions}

The PICC tip position determined at the autonomous peak of the forward $\mathrm{P}$-wave is significantly better than that at the forward P-wave amplitude being $50-80 \%$ of the QRS main wave when PICC inserted by IC-ECG.

\section{Acknowledgments}

We would like to thank the VAC team nurses who judiciously maintain the PICC database and Elise for the English language revision.

Funding: This study was supported by B. Braun Anaesthesia Science Research Foundation (BBFD-2015-16).

\section{Footnote}

Reporting Checklist: The authors have completed the STROBE reporting checklist. Available at https://dx.doi. org/10.21037/apm-21-1893

Data Sharing Statement: Available at https://dx.doi. org/10.21037/apm-21-1893

Peer Review File: Available at https://dx.doi.org/10.21037/ apm-21-1893

Conflicts of Interest: All authors have completed the ICMJE uniform disclosure form (available at https://dx.doi. org/10.21037/apm-21-1893). The authors have no conflicts of interest to declare.

Etbical Statement: The authors are accountable for all aspects of the work in ensuring that questions related to the accuracy or integrity of any part of the work are appropriately investigated and resolved. The study was conducted in accordance with the Declaration of Helsinki (as revised in 2013). The study was approved by the Institutional Review Board of Peking University Cancer Hospital and informed consent was taken from all the patients or their next of kin.

Open Access Statement: This is an Open Access article distributed in accordance with the Creative Commons Attribution-NonCommercial-NoDerivs 4.0 International License (CC BY-NC-ND 4.0), which permits the noncommercial replication and distribution of the article with the strict proviso that no changes or edits are made and the original work is properly cited (including links to both the formal publication through the relevant DOI and the license). See: https://creativecommons.org/licenses/by-nc-nd/4.0/.

\section{References}

1. Pittiruti M, Pelagatti F, Pinelli F. Intracavitary electrocardiography for tip location during central venous catheterization: A narrative review of 70 years of clinical studies. J Vasc Access 2020. [Epub ahead of print]. doi: $10.1177 / 1129729820929835$.

2. Society IN. Infusion therapy standards of practice. J Infus Nurs 2016;39.

3. Liu YJ, Dong L, Lou XP, et al. Evaluating ECG-aided tip localization of peripherally inserted central catheter in patients with cancer. Int J Clin Exp Med 2015;8:14127-9.

4. Mack V, Nißler D, Kasikci D, et al. Magnetic tracking and electrocardiography-guided tip confirmation system versus fluoroscopy for placement of peripherally inserted central catheters: a randomized, noninferiority comparison. Cardiovasc Intervent Radiol 2020;43:1891-7.

5. Yin YX, Gao W, Li XY, et al. Insertion of peripherally inserted central catheters with intracavitary electrocardiogram guidance: A randomized multicenter study in China. J Vasc Access 2019;20:524-9.

6. Pan KH, Gu DY, Zhou JC, et al. The carina is approximately $1-2 \mathrm{~cm}$ above the pericardial reflection among Chinese patients. J Thorac Dis 2014;6:845-9. 
7. Song YG, Byun JH, Hwang SY, et al. Use of vertebral body units to locate the cavoatrial junction for optimum central venous catheter tip positioning. Br J Anaesth 2015;115:252-7.

8. Pittiruti M, Bertollo D, Briglia E, et al. The intracavitary ECG method for positioning the tip of central venous catheters: results of an Italian multicenter study. J Vasc Access 2012;13:357-65.

9. Lee H, Mansouri M, Tajmir S, et al. A Deep-Learning System for Fully-Automated Peripherally Inserted Central Catheter (PICC) Tip Detection. J Digit Imaging 2018;31:393-402.

10. Schumacher I, Haste P. The Impact of Experience on Fluoroscopy Time for Peripherally Inserted Central Venous Catheters in a Pediatric Population: A Retrospective Review. Proceedings of IMPRS 2020;3.

11. Kim YO, Chung CR, Gil E, et al. Safety and feasibility of ultrasound-guided placement of peripherally inserted central catheter performed by neurointensivist in neurosurgery intensive care unit. PLoS One 2019;14:e0217641.

12. Jumani K, Advani S, Reich NG, et al. Risk factors for peripherally inserted central venous catheter complications in children. JAMA Pediatr 2013;167:429-35.

13. Luciani A, Clement O, Halimi P, et al. Catheter-related upper extremity deep venous thrombosis in cancer patients: a prospective study based on Doppler US. Radiology 2001;220:655-60.

14. Yu C, Shulan L, Juan W, et al. The accuracy and safety of using the electrocardiogram positioning technique in localizing the peripherally inserted central catheter tip position: A systematic review and meta-analysis. Nursing

Cite this article as: Wang X, Yang Y, Dong J, Wang X, Zheng Y, Chen J, Shen Y, Wang H. A comparative study on the tip position of peripherally inserted central catheter inserted at two forward $\mathrm{P}$-wave amplitudes by intracavitary electrocardiogram in cancer patients. Ann Palliat Med 2021;10(10):10228-10235. doi: 10.21037/apm-21-1893
Open 2021. [Epub ahead of print]. doi: 10.1002/nop2.932.

15. Shah M, Dufendach K, Schapiro A, et al. Comparison of Various Machine Learning Models to Identify Peripherally Inserted Central Catheter (PICC) Tip Position from Radiology Reports. Am Acad Pediatrics; 2021.

16. Vesely TM, Beathard G, Ash S, et al. A position statement from the American Society of Diagnostic and Interventional Nephrology. Semin Dial 2007;20:359-64.

17. Amerasekera SS, Jones CM, Patel R, et al. Imaging of the complications of peripherally inserted central venous catheters. Clin Radiol 2009;64:832-40.

18. Mahlon MA, Yoon HC. CT angiography of the superior vena cava: normative values and implications for central venous catheter position. J Vasc Interv Radiol 2007;18:1106-10.

19. Baskin KM, Jimenez RM, Cahill AM, et al. Cavoatrial junction and central venous anatomy: implications for central venous access tip position. J Vasc Interv Radiol 2008;19:359-65.

20. Cales YK, Rheingans J, Steves J, et al. Electrocardiogramguided peripherally inserted central catheter tip confirmation using a standard electrocardiogram machine and a wide-mouth electrocardiogram clip compared with traditional chest radiograph. J Vasc Access 2016;21:44-54.

21. Smith B, Neuharth RM, Hendrix MA, McDonnall D, Michaels AD. Intravenous electrocardiographic guidance for placement of peripherally inserted central catheters. J Electrocardiol 2010;43:274-8.

22. Argoti-Velasco Y, Carrillo-Torres O, Sandoval-Mendoza $\mathrm{R}$, et al. Proper electrocardiography-guided placement of a central venous catheter. Revista Médica del Hospital General de México 2018;81:262-7. 